\title{
In vitro studies of alcohol-induced liver injury in virally-infected human hepatocytes: Advantages and limitations
}

\author{
Natalia A. Osna, Srivatsan Kidambi
}

Infection of liver with hepatotropic viruses is exacerbated by alcohol abuse. Toxic effects of alcohol on virally infected cells are induced not by alcohol per se, but by alcohol metabolism. To efficiently metabolize alcohol, cells should express ethanol-metabolizing enzymes, alcohol dehydrogenase $(\mathrm{ADH})$ and cytochrome P450E1 (CYP2E1) that convert alcohol to acetaldehyde and generate reactive oxygen species (ROS). These enzymes are highly expressed in hepatocytes, making them the primary site of ethanol metabolism. All toxic effects of ethanol exposure to hepatocytes, which dose and time-dependently modulate viral replication, can be attributed to ethanol metabolism. Recently, we have shown that short-term exposure of HCV-infected cells to acetaldehyde enhances viral replication, while long-term exposure pushes cells to apoptosis $[1,2]$. These effects were not observed if liver cells are unable to metabolize ethanol. Unfortunately, most of ethanol studies on HCVinfected and HBV-infected hepatocytes are performed on hepatoma cell lines (HepG2 and Huh7 cells), which serve as the surrogative in vitro hepatocyte models. Most of hepatoma cells do not express ADH and CYP2E1 and thus, are not affected by ethanol metabolism, making the obtained results questionable in terms of the effects of ethanol metabolism. Furthermore, human primary

Natalia A. Osna ${ }^{1}$, Srivatsan Kidambi²

Affiliations: ${ }^{1}$ Research Service, Veterans Affairs NebraskaWestern lowa Health Care System, Department of Internal Medicine, University of Nebraska Medical Center, Omaha, Nebraska, USA; '2Department of Chemical Engineering, University of Nebraska-Lincoln, Nebraska, USA.

Corresponding Author: Natalia A. Osna, MD, PhD, Internal Medicine, UNMC, Veterans Affairs Nebraska-Western lowa Health Care System, 4101 Woolworth Ave, Omaha, NE 68105, USA; Email: nosna@unmc.edu

Received: 11 November 2017

Published: 16 November 2017 hepatocytes that can be virally infected and metabolize alcohol, after $24 \mathrm{hr}$ of collagen plating undergo fast de-differentiation, lose the expression of ethanolmetabolizing enzymes [3] and sensitivity to oxidative stress.

Since infection of hepatocytes with viruses requires the culturing for at least 3-4 days followed by ethanol treatment for another $48 \mathrm{hr}$, these cells cannot produce acetaldehyde via both $\mathrm{ADH}$ and $\mathrm{CYP} 2 \mathrm{E} 1$ or generate ROS via CYP2E1 by the time of ethanol exposure. Thus, special culturing conditions should be used to preserve the expression of ethanol-metabolizing enzymes and normal cell functions. This becomes possible if hepatocytes are plated on plates coated with Matrigel (commercially available $3 \mathrm{D}$ system) that preserve their functionality for about 10 days. The disadvantage of Matrigel bilayer is related to the presence of unknown amount of various growth factors, which is difficult to control due to the batch-to-batch difference. To overcome this limitation, we have developed an innovative patented technology which utilizes polyelectrolyte multilayer (PEM) film coating on top of the polydimethylsiloxane (PDMS) surface resulting in improved cell adhesion on synthetic PDMS surfaces without the use of adhesive ligands. These synthetic biomaterials are well-known to provide better control of mechanical and adhesive properties, have low toxicity and high thermal stability $[4,5]$. The PDMS is a very attractive material for cell biology studies, but does not support long-term culturing. Thus, it was modified using PEM films to improve its adhesive properties for culturing of primary hepatocytes alone or in combination with other liver cells (patterned co-culture) [6-9]. We observed that the primary hepatocytes maintained both $\mathrm{ADH}$ and CYP2E1 protein expression in soft (2 $\mathrm{kPa}$ ) PEM coated PDMS substrates for up to eight days. This data demonstrates that soft substrates are ideal for extending primary hepatocytes function in in-vitro conditions. Our preliminary data obtained on HCV-exposed and HIV-exposed hepatocytes clearly demonstrate the detrimental effects of ethanol treatment when cells are plated on these polymers. This happens because alcohol exposure stabilizes ethanol-metabolizing enzymes $\mathrm{ADH}$ 
and CYP2E1) in hepatocytes for at least eight days after plating (comparable to the result of plating in Matrigel) and supports cell infectivity without signs of hepatocyte de-differentiation and morphological changes. We believe that this approach will be very useful for in vitro studies of alcohol effects on virally infected hepatocytes. Thus, using our synthetic PDMS substrates for hepatocyte plating, we will control the physiologically relevant effects of ethanol metabolism on viral replication during longterm in vitro hepatocyte culturing, thereby mimicking the events observed in alcoholic patients infected with hepatotropic viruses.

\section{REFERENCES}

1. Ganesan M, Natarajan SK, Zhang J, et al. Role of apoptotic hepatocytes in HCV dissemination: Regulation by acetaldehyde. Am J Physiol Gastrointest Liver Physiol 2016 Jun 1;310(11):G930-40.

2. Ganesan M, Poluektova LY, Tuma DJ, Kharbanda KK, Osna NA. Acetaldehyde disrupts interferon alpha signaling in hepatitis $\mathrm{C}$ virus-infected liver cells by up-regulating USP18. Alcohol Clin Exp Res 2016 Nov;4O(11):2329-38.

3. Godoy P, Hewitt NJ, Albrecht U, et al. Recent advances in $2 \mathrm{D}$ and $3 \mathrm{D}$ in vitro systems using primary hepatocytes, alternative hepatocyte sources and nonparenchymal liver cells and their use in investigating mechanisms of hepatotoxicity, cell signaling and ADME. Arch Toxicol 2013 Aug;87(8):1315-530.

4. ParkJH, Park KD, BaeYH.PDMS-based polyurethanes with MPEG grafts: Synthesis, characterization and platelet adhesion study. Biomaterials 1999 May;20(10):943-53.

5. Ertel SI, Ratner BD, Kaul A, Schway MB, Horbett TA. In vitro study of the intrinsic toxicity of synthetic surfaces to cells. J Biomed Mater Res 1994 Jun;28(6):667-75.

6. Kidambi S, Sheng L, Yarmush ML, Toner M, Lee I, Chan C. Patterned co-culture of primary hepatocytes and fibroblasts using polyelectrolyte multilayer templates. Macromol Biosci 2007 Mar 8;7(3):34453 .

7. Kidambi S, Yarmush RS, Novik E, Chao P, Yarmush ML, Nahmias Y. Oxygen-mediated enhancement of primary hepatocyte metabolism, functional polarization, gene expression, and drug clearance. Proc Natl Acad Sci U S A 2009 Sep 15;106(37):157149.

8. Natarajan V, Berglund EJ, Chen DX, Kidambi S. Substrate stiffness regulates primary hepatocyte functions. RSC Advances 2015;5:80956-66.

9. Kidambi S, Udpa N, Schroeder SA, Findlan R, Lee I, Chan C. Cell adhesion on polyelectrolyte multilayer coated polydimethylsiloxane surfaces with varying topographies. Tissue Eng 2007 Aug;13(8):2105-17.
Keywords: Alcohol metabolism, Hepatocyte, Hepatotropic viruses, Synthetic biomaterials

\section{How to cite this article}

Osna NA, Kidambi S. In vitro studies of alcohol-induced liver injury in virally-infected human hepatocytes: Advantages and limitations. Int $\mathrm{J}$ Hepatobiliary Pancreat Dis 2017;7:50-52.

Article ID: 100073IJHPDNO2017

$* * * * * * * * *$

doi:10.5348/ijhpd-2017-73-ED-9

$* * * * * * * * *$

\section{Author Contributions}

Natalia A. Osna - Substantial contributions to conception and design, Acquisition of data, Analysis and interpretation of data, Drafting the article, Revising it critically for important intellectual content, Final approval of the version to be published

Srivatsan Kidambi - Substantial contributions to conception and design, Acquisition of data, Analysis and interpretation of data, Drafting the article, Revising it critically for important intellectual content, Final approval of the version to be published

\section{Guarantor of Submission}

The corresponding author is the guarantor of submission.

\section{Source of Support}

None

\section{Conflict of Interest}

Authors declare no conflict of interest.

\section{Copyright}

(C) 2017 Natalia A. Osna et al. This article is distributed under the terms of Creative Commons Attribution License which permits unrestricted use, distribution and reproduction in any medium provided the original author(s) and original publisher are properly credited. Please see the copyright policy on the journal website for more information. 
Access full text article on other devices

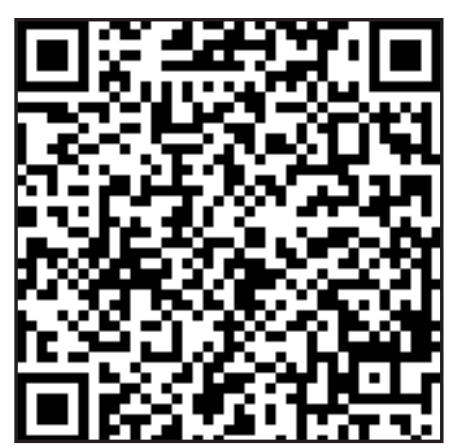

Access PDF of article on other devices

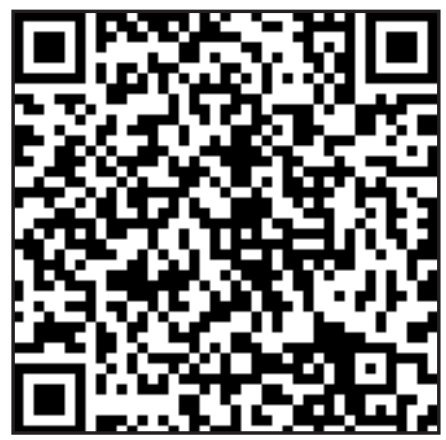

